\title{
Effects of Chronic Protein-Calorie Malnutrition on Small Intestinal Repair after an Acute Bacterial Enteritis: A Study in Infant Rabbits
}

\author{
J. DECKER BUTZNER AND D. GRANT GALL
}

Intestinal Diseases Research Unit, Health Sciences Centre, The University of Calgary, Calgary, Alberta, Canada

\begin{abstract}
The aim of this study was to determine if recovery of intestinal function in infant rabbits subjected to protein-calorie malnutrition was delayed as a result of inflammatory injury induced by an experimental bacterial enteritis. Rabbits were malnourished by expanding litter size at 7 days of age and infecting undernourished animals and dietary controls with Yersinia enterocolitica at either 17 or 21 days of age. Intestinal morphology and function were evaluated in infected and noninfected animals from both dietary groups at 27 days of age. Undernutrition alone significantly reduced animal weight, small intestinal weight, segmental jejunal and ileal mucosal weight, villus height, crypt depth, disaccharidase activities, mucosal protein and DNA contents, but increased ileal short-circuited glucose-stimulated $\mathrm{Na}^{+}$absorption compared to controls. The jejunum of undernourished rabbits at 6 days postinfection exhibited an intestinal injury, as evidenced by a mild inflammatory infiltrate and further reductions in villus height, mucosal weight, lactase activity, protein and DNA content, not seen in infected dietary controls. Jejunal recovery was complete by 10 days postinfection. In the ileum of infected animals of both dietary groups at 6 days postinfection, a severe inflammatory response, decreased villus height, elongated crypts, and depressed stimulation of $\mathrm{Na}^{+}$ absorption by glucose was observed. By 10 days after infection, while recovery was nearly complete in dietary controls, intestinal damage persisted in the undernourished rabbits, as evidenced by absent glucose-stimulated $\mathrm{Na}^{+}$ absorption, continued severe inflammation and microabscess formation. We conclude that intestinal injury is more severe and chronic in the undernourished, compared to dietary control infant rabbits subjected to an acute bacterial enteritis. (Pediatr Res 23:408-413, 1988)
\end{abstract}

\section{Abbreviations}

PD, transepithelial potential difference

I $_{\text {sc }}$, short-circuit current

$G$, tissue conductance

$J_{\mathrm{ms}}^{\mathrm{Na}}$, mucosal to serosa sodium flux

$\mathbf{J}_{\mathrm{sm}}^{\mathrm{Na}}$, serosal to mucosa sodium flux

$\mathbf{J}_{\text {net, }}^{\mathrm{Na}}$, net sodium flux
The combination of malnutrition and diarrheal disease is the leading cause of death in children under the age of $5 \mathrm{yr}$ (1). Most of these children suffer from primary protein-calorie malnutrition which is aggravated by severe diarrhea. Clinical studies have shown that acute enteric infections aggravate and potentiate nutrient deficiencies. In turn, the inability of the nutrient-deprived host to respond appropriately to an infectious insult leads to prolonged diarrheal illness (2). Little is known about the nature of the interactions between enteric infections and the intestinal epithelium in the chronically malnourished host. The aim herein was to examine the recovery of intestinal function after an acute infectious enteritis in an infant animal model of protein-calorie malnutrition. Our results indicate that intestinal damage is more severe and recovery delayed in the malnourished infant than in dietary controls after an experimental inflammatory insult.

\section{METHODS}

Does and litters of New Zealand White rabbits were quarantined at 4 days after birth and observed over 3 days for signs of infection. Protein-calorie malnutrition was induced in the experimental group by combining two litters at 7 days of age to increase litter size to $11-13$ pups. To insure maternal health and to prevent access to solid food, does were alternated at 24-h intervals. Does caged with the pups had access to water only. Controls were derived by combining two litters and then reducing litter size to six to seven animals. As with the experimental group, does were switched daily but access to rabbit food was permitted throughout the study. Animals were weighed on alternate days. On either day 17 or 21 after an 18-h fast, animals from both dietary groups were infected with Yersinia enterocolitica strain MCH 700S (serotype 0:3), originally isolated from a human patient with diarrhea (3). Animals were infected by orogastric intubation with $10^{9}$ organisms suspended in $1 \mathrm{ml}$ of $10 \% \mathrm{NaHCO}$ solution (4). Preliminary studies established that this dose reproducibly induced infection in animals of both dietary groups. Noninfected controls from both dietary groups also underwent an 18-h fast. Weight gain, clinical status, and presence of diarrhea were assessed daily. On day 27 , noninfected animals and animals infected 6 and 10 days previously were killed by cervical dislocation and blood was collected for measurement of total protein and albumin.

The small intestine from the ligament of Treitz to the most proximal attachment of the mesoappendix was removed; unstretched segments were measured with a fixed measuring device and cut as outlined. The $15-\mathrm{cm}$ segment of ileum ending at the mesoappendix was removed, flushed with cold isotonic saline, and used for ion transport studies. Two additional $12-\mathrm{cm}$ segments were removed; a proximal segment beginning at the ligament of Trietz and a distal segment just proximal to the segment used for transport studies. These later segments were flushed and weighed. A 2 -cm segment was removed for micro-
Received October 5, 1987; accepted December 11, 1987.
Supported by the Intestinal Diseases Research Unit, University of Calgary, the Medical Research Council of Canada and the Canadian Foundation for Ileitis and Colitis.

Reprints and correspondence to J. D. Butzner, M.D, Department of Pediatrics Health Sciences Centre, 3330 Hospital Drive N.W., Calgary, Alberta, Canada, T2N $4 \mathrm{~N} 1$. 
scopic studies and from the remaining $10 \mathrm{~cm}$, the mucosa was scraped, weighed, homogenized in $2.5 \mathrm{mM}$ EDTA $(100 \mathrm{mg} / \mathrm{ml})$ at $\mathrm{pH} 7.4$ and frozen for later estimation of mucosal enzyme activities, protein, and DNA content. Swabs obtained from the jejunum, ileum, and cecum of both noninfected and infected animals were plated onto Salmonella-Shigella media.

Tissue for light microscopy was fixed in $4 \%$ phosphate-buffered formalin, dehydrated, embedded in paraffin wax, sectioned, and stained with hemotoxylin and eosin. Coded sections were examined by one observer without prior identification of the section. Villus height and crypt depth were measured in 10-12 properly oriented crypt-villus units per segment using a calibrated micrometer.

Homogenates were assayed for sucrase and lactase activities by the method of Dahlquist (5), and protein content by the method of Lowry et al. DNA content was measured by the method of Hinegardner (7) using thymus DNA (Sigma Chemical, St. Louis, MO) as a standard.

For ion transport studies, the mucosa of the distal segment was stripped of its overlying muscle and serosa and four adjacent segments were mounted in short-circuited Ussing chambers, exposing a $0.4 \mathrm{~cm}^{2}$ surface area to $10 \mathrm{ml}$ of oxygenated Kreb'sbicarbonate buffer at $37^{\circ} \mathrm{C}$ and $\mathrm{pH} 7.4 \pm 0.1$ (8). Glucose (10 $\mathrm{mM})$ was added to the serosal side and mannitol $(10 \mathrm{mM})$ to the mucosal side. Ten $\mu \mathrm{Ci}^{22} \mathrm{Na}$ (Amersham, Willowdale, Ontario, Canada) was added to either the mucosal or serosal side of each tissue segment. The spontaneous PD was determined and the tissue clamped at zero voltage by continuously introducing an appropriate Isc with an automatic voltage clamp (DVC 1000, World Precision Instruments, New Haven, CT), except for $20 \mathrm{~s}$ every 5 min when open potential difference was measured. G was calculated from PD and Isc according to Ohm's law (9). After a 15 -min equilibration period, samples for ion fluxes were obtained from the mucosal and serosal chambers at 5-min intervals for $15 \mathrm{~min}$. Immediately after completion of the basal period, glucose and mannitol (final concentration $30 \mathrm{mM}$ glucose and $10 \mathrm{mM}$ mannitol) were added to both sides of the tissue and after 15 min of equilibration, flux measurements were repeated. Tissue pairs were discarded if conductances varied by more than $30 \%$. Steady state unidirectional $\mathbf{J}_{\mathrm{ms}}^{\mathrm{Na}}, \mathbf{J}_{\mathrm{sm}}^{\mathrm{Na}}$, and $\mathbf{J}_{\mathrm{net}}^{\mathrm{Na}}$ sodium fluxes $\mu \mathrm{Eq} \cdot \mathrm{cm}^{-2} \cdot \mathrm{h}^{-1}$ ) were calculated in paired tissues in the absence of an electrochemical gradient across the tissue by measuring three consecutive 5-min fluxes and one overall 15-min flux during each of the two periods. Data are expressed as mean \pm SEM and statistical comparisons were made using Student's $t$ test. Mortality data were analyzed by the $\chi^{2}$ method.

\section{RESULTS}

Clinical. Initial mean body weights for the two dietary groups did not differ on day 7 when litters were combined (Table 1). By 9 days of age, 2 days after initiating the restricted diet, the mean cumulative weight gain of the undernourished rabbits was significantly less than the controls; this difference persisted for the duration of the study (Fig. 1). Weights of the noninfected animals and the animals to be infected in the respective dietary groups did not differ prior to infection at 17 or 21 days (data not shown). After infection, there was no significant difference in weight gain between infected and noninfected animals on either the control diet or the restricted nutrient intake (Fig. 1). At the time of study, mean body weights of both infected and noninfected undernourished animals were significantly less than those of noninfected dietary controls (Table 1 ).

All animals infected with $Y$. enterocolitica developed diarrhea. In the majority, this consisted of a mild diarrheal illness lasting 1-2 days which occurred between 4 and 6 days postinfection. However, one infected animal in the control diet group and six in the undernourished group developed severe persistent diarrhea, subsequent dehydration, and died between 6 and 8 days postinfection. The difference in mortality was not significant and data from these animals are not included in the analyses. Does, although housed with infected pups, remained clinically well throughout the study. All infected animals from both dietary groups had positive ileocecal cultures for $Y$. enterocolitica at the time of study. In both dietary groups, jejunal cultures were positive in a similar number of animals at 6 days (control, four of seven animals; undernourished, five of seven) and 10 days (control, two of nine; undernourished, five of nine) postinfection. No enteric pathogens were cultured from noninfected animals in either dietary group. Serum protein and albumin concentrations were similar for all animals in both dietary groups.

Intestinal response to diet and infection. Morphology (Fig. 2).

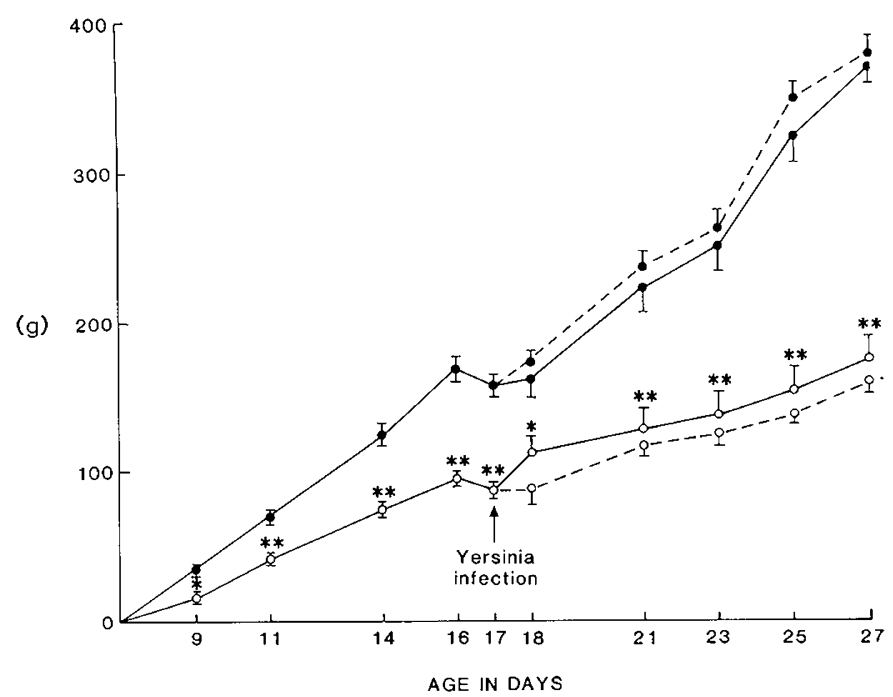

Fig. 1. Mean cumulative weight gains of rabbits in g. Animals undernourished $(O)$ from age 7 days gained less than controls $(\bullet)$ at all time periods from 9 days $\left({ }^{*} p<0.01,{ }^{* *} p<0.001\right)$. Rabbits infected with $Y$. enterocolitica at 17 days (-_-_) are compared with noninfected rabbits $(\longrightarrow)$ in the same dietary group.

Table 1. Mean body and total small intestinal wt*

\begin{tabular}{|c|c|c|c|c|c|c|}
\hline & \multicolumn{3}{|c|}{ Control diet } & \multicolumn{3}{|c|}{ Undernourished diet } \\
\hline & NIC & $6 \mathrm{D}$ & $10 \mathrm{D}$ & NIU & $6 \mathrm{D}$ & $10 \mathrm{D}$ \\
\hline \multicolumn{7}{|l|}{ Body wt (g) } \\
\hline Day 7 & $137 \pm 5$ & $133 \pm 4$ & $130 \pm 6$ & $127 \pm 7$ & $125 \pm 7$ & $138 \pm 10$ \\
\hline Day 27 & $519 \pm 16$ & $492 \pm 12$ & $520 \pm 17$ & $289 \pm 20 \dagger$ & $239 \pm 16 \dagger$ & $313 \pm 10 \dagger$ \\
\hline Intestinal wt (g) & $8.4 \pm 0.7$ & $8.9 \pm 0.8$ & $8.7 \pm 0.5$ & $4.9 \pm 0.4 \dagger$ & $6.1 \pm 0.6 \dagger$ & $6.4 \pm 0.5+\neq$ \\
\hline$n$ & 7 & 7 & 9 & 10 & 7 & 9 \\
\hline
\end{tabular}

* Values are mean \pm SEM of NIC (noninfected controls), NIU (noninfected undernourished) animals $6 \mathrm{D}$ (6 days) and 10D (10 days) postinfection, where $n$ is the number of animals.

$\dagger p<0.01$ compared to NIC.

$\ddagger p<0.05$ compared to NIU 

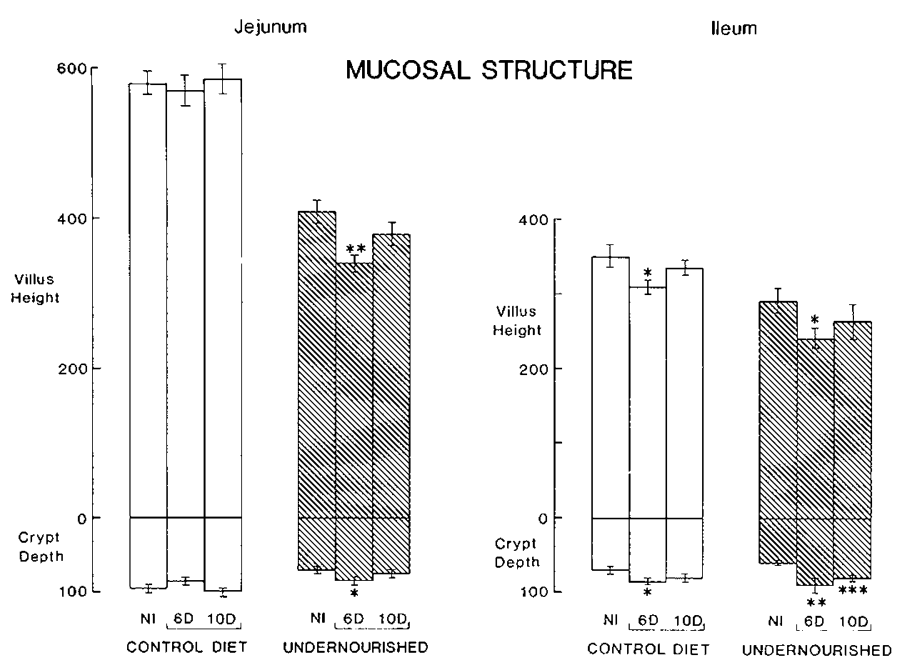

Fig. 2. Jejunal and ileal mucosal structure $(\mu)$ in dietary controls and undernourished animals for noninfected $(N I)$ and animals 6 days $(6 D)$ and 10 days $(10 D)$ after infection with $Y$. enterocolitica. Values are mean \pm SEM, ${ }^{*} p<0.05,{ }^{* *} p<0.01,{ }^{* * *} p<0.001$ comparing infected to respective NI dietary group.

In animals with a normal dietary intake, infection did not alter jejunal villus-crypt dimensions or cause mucosal inflammation. In the ileum, infection led to a significant decrease in villus height and an increase in crypt depth by 6 days. This was associated with an inflammatory infiltrate in the lamina propria consisting of neutrophils, lymphocytes, and macrophages. By 10 days postinfection, mucosal architecture had recovered and inflammation had resolved.

Malnutrition alone significantly decreased $(p<0.05)$ jejunal and ileal villus height and crypt depth compared to noninfected dietary controls (Fig. 2) with no evidence of mucosal inflammation or damage. In contrast to the lack of jejunal morphological alterations caused by infection in dietary controls, infection in the undernourished group altered mucosal structure in the jejunum at 6 days. Compared to noninfected animals, villus height was depressed, crypt depth increased, and an inflammatory infiltrate of neutrophils, lymphocytes, and macrophages was present in the lamina propria surrounding crypts. These changes resolved by 10 days postinfection. The ileum of infected undernourished animals demonstrated more persistent abnormalities. At 6 days postinfection, villus height was decreased and crypt depth increased. This was associated with an inflammatory response in the lamina propria adjacent to crypts. Whereas villus height had recovered at 10 days postinfection, crypt depth remained significantly increased and the inflammatory response was more extensive. The inflammatory infiltrate extended to involve both villi and crypts and microabscesses containing bacteria were apparent.

Intestinal and Mucosal Wet Weight, Protein, and DNA Content. In dietary controls, infection caused only minor changes in segmental weights (Fig. 3) compared to noninfected rabbits on the control diet. Total wet weight of the jejunal segment was decreased and ileal mucosal wet weight increased 6 days postinfection with recovery by 10 days. Total small intestinal weight (Table 1) along with segmental mucosal protein and DNA contents (Fig. 4) did not differ from values of noninfected dietary controls.

Malnutrition alone caused a significant $(p<0.01)$ decrease in total small intestinal weight (Table 1), and total wet weight, mucosal wet weight (Fig. 3), protein and DNA contents (Fig. 4) in segments of jejunum and ileum compared to noninfected dietary controls. In the jejunum of infected malnourished animals, total wet weight, mucosal wet weight, protein and DNA contents were further depressed at 6 days, recovering by 10 days

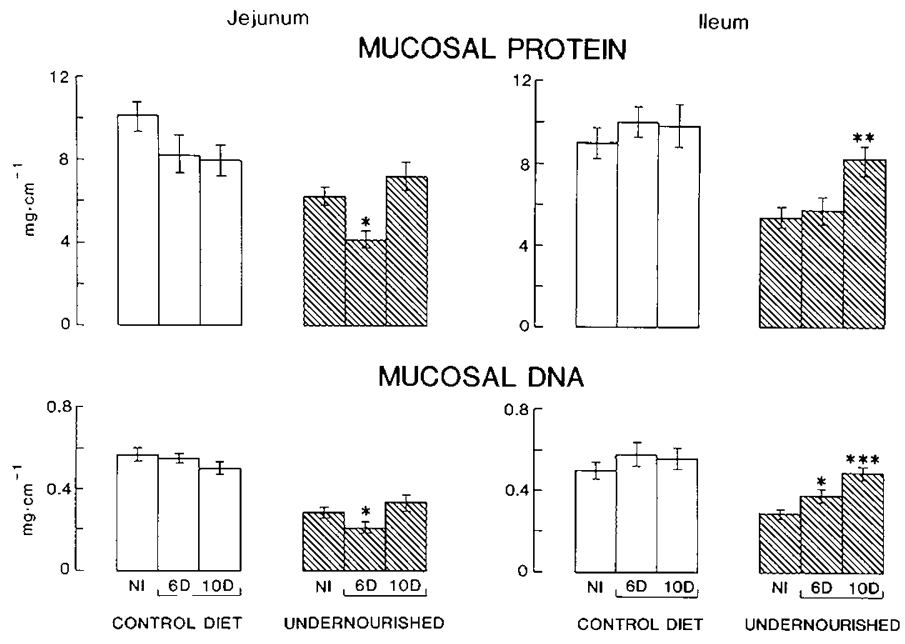

Fig. 4. Jejunal and ileal mucosal protein and DNA content (mg. $\mathrm{cm}^{-1}$ ) in dietary controls and undernourished animals. Legends and notations as in Figure 2.

compared to noninfected malnourished animals (Figs. 3 and 4). In contrast, ileal total and mucosal wet weights (Fig. 3) increased with time, reaching significance by 10 days postinfection. This resulted in an increase in total small intestinal weight at 10 days postinfection (Table 1) and was associated with a significant increase in ileal mucosal protein at 10 days and ileal mucosal DNA at 6 and 10 days postinfection (Fig. 4) compared to the noninfected nutrient deprived group.

Mucosal Enzyme Activity (Fig. 5). In animals on a normal diet, infection significantly decreased sucrase activity in the jejunum and ileum at 6 days. There was recovery of activity in the jejunum by 10 days but not in the ileum. Lactase activity was not effected by infection. Malnutrition by itself led to a significant $(p<0.05)$ depression of sucrase and lactase activities in both regions of the small intestine. Infection contributed to a further reduction in jejunal lactase at 6 days but did not alter jejunal sucrase or ileal sucrase and lactase.

Ileal Sodium Transport and Electrical Activity (Table 2). In animals receiving a normal dietary intake, PD, Isc, or net $\mathrm{Na}^{+}$ fluxes under basal conditions in the ileum were not altered at 
either 6 or 10 days postinfection whereas unidirectional fluxes $\left(\mathrm{J}_{\mathrm{ms}}^{\mathrm{Na}}, J_{\mathrm{sm}}^{\mathrm{Na}}\right)$ and $\mathrm{G}$ were significantly decreased $(p<0.05)$ compared to noninfected dietary controls (Table $2 A$ ). The addition of 30 $\mathrm{mM}$ glucose in noninfected controls, as expected, stimulated net $\mathrm{Na}^{+}$absorption due to an increase in the $J_{\mathrm{ms}}^{\mathrm{Na}}$ flux. PD and Isc were also increased. The response to glucose was blunted 6 days after infection. The presence of glucose failed to produce a significant increment in net $\mathrm{Na}^{+}$absorption or in the $J_{\mathrm{ms}}^{\mathrm{Na}}$ flux. $\mathrm{PD}$ and Isc did increase but the increment was significantly less $(p<0.05)$ than that seen in controls. By 10 days postinfection, glucose-stimulated $\mathrm{Na}^{+}$transport had recovered and the presence of glucose increased PD, Isc, $J_{\mathrm{ms}}^{\mathrm{Na}}$ and $J_{\text {net. }}^{\mathrm{Na}}$.

In noninfected undernourished animals, under basal conditions, unidirectional $\mathrm{Na}^{+}$fluxes were significantly $(p<0.05)$ greater in the ileum compared to dietary controls while net fluxes, PD, Isc, and $\mathrm{G}$ did not differ (Table $2 A$ and $B$ ). The addition of glucose significantly increased $\mathrm{J}_{\mathrm{ms}}^{\mathrm{Na}}$ and $\mathrm{J}_{\text {net }}^{\mathrm{Na}}$ above basal levels in noninfected undernourished animals while $\mathbf{J}_{\mathrm{sm}}^{\mathrm{Na}}$ was unaffected. However, the increment in $\mathrm{Na}^{+}$absorption and $\mathrm{J}_{\mathrm{ms}}^{\mathrm{Na}}$ produced by the addition of glucose was significantly greater in undernourished animals than controls $\left(\mathrm{J}_{\text {net }}^{\mathrm{Na}}+5.2 \pm 0.8\right.$ versus $+2.5 \pm 0.5$

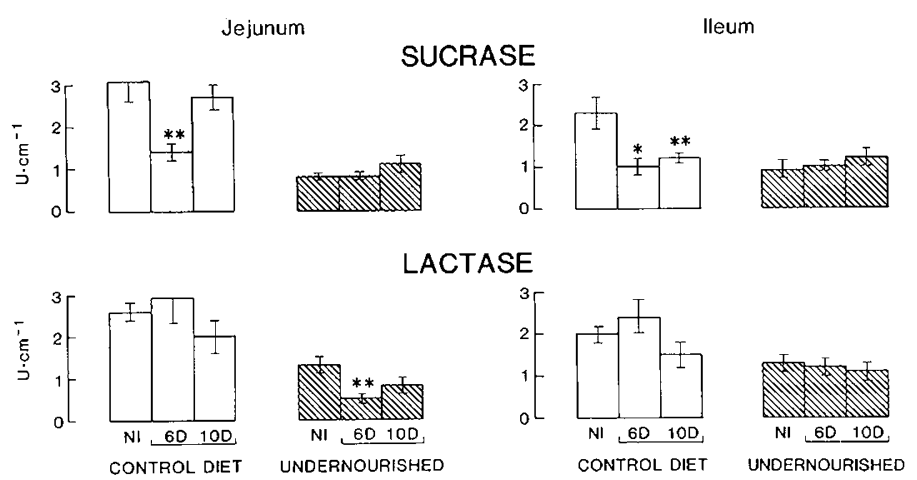

Fig. 5. Jejunal and ileal mucosal sucrase and lactase activities (U. $\mathrm{cm}^{-1}$ ) in dietary controls and undernourished animals. Legends and notations as in Figure 2. $\mu \mathrm{Eq} \cdot \mathrm{cm}^{-2} \cdot \mathrm{h}^{-1}, p<0.02 ; \mathrm{J}_{\mathrm{ms}}^{\mathrm{Na}}+5.4 \pm 0.6$ versus $+3.7 \pm 0.4, p$ $<0.05$ ). The presence of glucose also stimulated PD, Isc, and G in the undernourished group.

Uñdernourished animals studied 6 and 10 days postinfection demonstrated no alterations in ileal net $\mathrm{Na}^{+}$transport under basal conditions when compared to the noninfected undernourished group (Table $2 B$ ). However, PD and Isc were increased ( $p$ $<0.05$ ) and unidirectional fluxes and $\mathrm{G}$ were decreased $(p<$ 0.01 ) in the basal periods after infection. Glucose failed to stimulate ileal $\mathrm{Na}^{+}$absorption 6 days after infection in undernourished animals, just as it failed in infected animals on a normal diet. This defect persisted in the undernourished group at 10 days postinfection. Glucose still failed to stimulate $\mathrm{Na}^{+}$ absorption in infected undernourished rabbits whereas the response to glucose had fully recovered in the control dietary group. In the malnourished animals at 6 days postinfection, glucose increased unidirectional Na fluxes, and $\mathrm{G}$ but not PD, Isc, and $J_{\text {net. }}^{\mathrm{Na}}$ At 10 days not only did PD, Isc, and $J_{\text {net }}^{\mathrm{Na}}$ fail to respond to the addition of glucose, but unidirectional fluxes failed to respond as well.

\section{DISCUSSION}

The immature intestine of the developing infant is susceptible to damage inflicted by an acute infectious enteritis. Animals receiving a normal dietary intake and infected with $Y$. enterocolitica developed a diarrheal illness lasting 1 to 2 days and had positive intestinal cultures. At the height of the illness, 6 days postinfection, abnormalities in the jejunum consisted of depressed wet weight and sucrase activity. Inflammation was not present and recovery had occurred by 10 days. In the ileum, the alterations were more dramatic. Six days after infection there was evidence of ileal mucosal inflammation, partial villus atrophy, and crypt hyperplasia. This was associated with functional derangements that included depressed sucrase activity, decreased unidirectional $\mathrm{Na}^{+}$fluxes, depressed $\mathrm{G}$, and blunted glucosestimulated $\mathrm{Na}$ transport. By 10 days the majority of the abnormalities had recovered and the inflammation had resolved in these animals. Infection in dietary controls inflicted a more extensive injury on the ileum than the jejunum, findings that are

Table 2. Sodium fluxes and electrical activities in short-circuited ileal epithelium*

\begin{tabular}{|c|c|c|c|c|c|c|}
\hline & Jms & $\mathrm{Jsm}$ & Jnet & Isc & $\mathrm{PD}$ & G \\
\hline \multicolumn{7}{|c|}{ A. Control diet } \\
\hline \multicolumn{7}{|c|}{ NIC } \\
\hline Basal & $14.5 \pm 0.8$ & $13.9 \pm 0.8$ & $+0.7 \pm 0.5$ & $2.8 \pm 0.3$ & $-1.8 \pm 0.4$ & $42.9 \pm 1.8$ \\
\hline Glucose & $18.2 \pm 1.0 \dagger$ & $15.0 \pm 0.8$ & $+3.2 \pm 0.6 \ddagger$ & $5.7 \pm 0.2 \S$ & $-3.4 \pm 0.1 \ddagger$ & $47.1 \pm 2.5$ \\
\hline \multicolumn{7}{|l|}{$6 \mathrm{D}$} \\
\hline Basal & $10.7 \pm 0.8$ & $11.7 \pm 0.9$ & $-1.0 \pm 0.7$ & $1.9 \pm 0.3$ & $-1.7 \pm 0.3$ & $31.1 \pm 0.3$ \\
\hline Glucose & $11.7 \pm 0.6$ & $12.2 \pm 0.2$ & $-0.5 \pm 0.4$ & $3.3 \pm 0.3 \dagger$ & $-2.7 \pm 0.3 \dagger$ & $32.1 \pm 0.4$ \\
\hline \multicolumn{7}{|l|}{$10 \mathrm{D}$} \\
\hline Basal & $9.5 \pm 0.5$ & $10.0 \pm 0.6$ & $-0.5 \pm 0.4$ & $2.5 \pm 0.1$ & $-2.4 \pm 0.2$ & $27.9 \pm 1.5$ \\
\hline Glucose & $11.0 \pm 0.4 \uparrow$ & $10.0 \pm 0.5$ & $+1.0 \pm 0.3 \ddagger$ & $3.6 \pm 0.1 \S$ & $-3.5 \pm 0.1 \ddagger$ & $26.8 \pm 0.5$ \\
\hline \multicolumn{7}{|c|}{ B. Undernourished diet } \\
\hline \multicolumn{7}{|c|}{ NIU } \\
\hline Basal & $17.7 \pm 0.9$ & $18.2 \pm 0.8$ & $-0.4 \pm 0.3$ & $2.8 \pm 0.2$ & $-1.7 \pm 0.1$ & $45.4 \pm 0.4$ \\
\hline Glucose & $23.1 \pm 1.4 \dagger$ & $18.3 \pm 0.8$ & $+4.8 \pm 0.8 \S$ & $5.2 \pm 0.2 \S$ & $-2.6 \pm 0.1 \S$ & $54.8 \pm 2.8 \ddagger$ \\
\hline \multicolumn{7}{|l|}{$6 \mathrm{D}$} \\
\hline Basal & $13.4 \pm 1.0$ & $13.6 \pm 0.7$ & $-0.1 \pm 0.6$ & $4.4 \pm 0.4$ & $-3.0 \pm 0.2$ & $39.3 \pm 0.2$ \\
\hline Glucose & $17.2 \pm 1.1 \dagger$ & $16.6 \pm 1.1 \dagger$ & $+0.6 \pm 0.3$ & $4.8 \pm 0.2$ & $-3.0 \pm 0.2$ & $51.1 \pm 1.9 \ddagger$ \\
\hline \multicolumn{7}{|l|}{$10 \mathrm{D}$} \\
\hline Basal & $11.5 \pm 0.7$ & $12.1 \pm 0.6$ & $-0.6 \pm 0.4$ & $3.5 \pm 0.2$ & $-2.6 \pm 0.1$ & $36.5 \pm 1.2$ \\
\hline Glucose & $13.8 \pm 0.9$ & $13.9 \pm 0.8$ & $-0.1 \pm 0.6$ & $4.1 \pm 0.3$ & $-2.6 \pm 0.2$ & $42.0 \pm 2.2 \dagger$ \\
\hline
\end{tabular}

* Values are mean \pm SEM of NIC (noninfected controls), NIU (noninfected undernourished) animals $6 \mathrm{D}$ (6 days) and 10D (10 days) postinfection. $\mathrm{J}$ and Isc are in $\mu \mathrm{Eq} \cdot \mathrm{cm}^{-2} \cdot \mathrm{h}^{-1}, \mathrm{PD}$ is in $\mathrm{mV}$, and $\mathrm{G}$ is in $\mathrm{mS} \cdot \mathrm{cm}^{-2}$.

$\dagger p<0.05$ comparing values in the basal period to the glucose period.

$\ddagger p<0.01$ comparing values in the basal period to the glucose period.

$\S p<0.001$ comparing values in the basal period to the glucose period. 
in keeping with previous observations of $Y$. enterocolitica infection in older animals $(4,10)$.

Litter expansion significantly reduced weight gain in undernourished animals after 2 days and resulted in a final body weight that was only $55 \%$ of controls. This corresponds with a clinical state of severe malnutrition or marasmus, defined as body weight equal or less than $60 \%$ of expected for age without edema or hypoalbuminemia (11). Although noninfected undernourished animals remained clinically healthy and enteric pathogen free, we noted alterations in intestinal structure and function compared to noninfected dietary controls. Intestinal weight, mucosal wet weight, protein content, DNA content, villus height, crypt depth and disaccharidase activities were decreased in jejunum and ileum. These findings are in keeping with a reduction in epithelial cell number previously noted in malnourished infant rats $(12,13)$ and rabbits (14). The impairment of intestinal growth appears to be the result of depressed enterocyte proliferation and delayed epithelial migration $(13,15)$. Other laboratories have shown that disaccharidase specific activities are preserved and sometimes increased in suckling animals subjected to protein-calorie malnutrition $(13,16,17)$. Inasmuch as specific activity is calculated per unit protein, the loss of mucosal protein may appear to preserve or elevate disaccharidase specific activity (18). When results are expressed per total intestine or per unit length of intestine as done herein, the loss of disaccharidase activity caused by mucosal hypoplasia becomes evident $(13,16)$. Malnutrition alone altered ileal transport function. Unidirec tional $\mathrm{Na}^{+}$fluxes were increased, suggesting a more porous epithelium and glucose-stimulated $\mathrm{Na}^{+}$absorption was enhanced compared to dietary controls. Similar findings were observed in the jejunum of undernourished piglets (19). Recent studies in adult rats subjected to semistarvation, indicate that this nutritional adaptation may be due to increased sodium and glucose uptake by brush border membrane vesicles (20). The mechanisms triggering the alterations in mucosal structure and function observed in the intestine of malnourished animals are unknown. Possibilities include effects resulting directly from nutrient deprivation or indirectly from hormonal responses induced by malnutrition. The alterations in intestinal transport observed in undernourished animals cannot be explained by immaturity alone. Whereas the intestine of 10- to 14-day-old rabbits demonstrates a similar low resistance ion flux, glucose-stimulated sodium absorption is deficient (10) compared to the enhanced transport noted in malnourished rabbits and piglets (19).

Infection with $Y$. enterocolitica inflicted further impact on the intestine of malnourished animals. In the jejunum 6 days postinfection, we observed evidence of brush border damage and mucosal inflammation. Villus height, total segmental weight, mucosal weight, protein content, DNA content, and lactase activity were further depressed and crypt depth increased compared to the noninfected nutrient-deprived animals. The inflammatory response observed in the jejunum of infected undernourished animals was not seen in the jejunum of infected dietary controls. These abnormalities had resolved by 10 days postinfection indicating that the undernourished animals were capable of initiating a repair process.

In the ileum, the additional insult of infection in malnourished animals resulted in mucosal inflammation, a further decrease in villus height, and an increase in crypt depth. Also $\mathrm{Na}^{+}$transport was altered. Unidirectional fluxes were decreased in the basal period and instead of enhanced glucose-stimulated $\mathrm{Na}^{+}$transport, as seen in the noninfected malnourished group, glucose failed to stimulate $\mathrm{Na}^{+}$absorption, a finding similar to that of infected dietary controls. The preservation of total segmental weight, mucosal weight and protein, and the increase in mucosal DNA in the ileum, despite evidence of epithelial injury, may be explained by the increased number of inflammatory cells. Abnormalities were still present 10 days after infection. Mucosal inflammation was more extensive with microabscess formation and evidence of epithelial dysfunction persisted. Although villus height recovered, crypts remained hyperplastic, and ileal weight, mucosal weight, protein, and DNA content were now significantly increased, findings in keeping with the marked inflammatory infiltrate. Unidirectional fluxes, PD, I, and $G$ under basal conditions remained depressed and glucose failed to stimulate $\mathrm{Na}^{+}$transport. The persistence of ileal abnormalities at 10 days in the malnourished animals contrasts with almost complete recovery in infected animals receiving a normal dietary intake.

The prolongation of inflammation and mucosal abnormalities in the ileum could possibly be explained by an increased severity of the initial injury or by an inability to clear the infecting organisms in the undernourished animals. Both of these explanations are unlikely, inasmuch as morphological and functional parameters were similar at 6 days. At 10 days, infected animals from both dietary groups remained colonized with $Y$. enterocolitica. Additional explanations include an inability of the immune system to limit tissue invasion or a delayed mucosal repair process. Both depressed immune function and decreased small intestinal epithelial proliferation are recognized complications of severe protein-calorie malnutrition $(13,15,19,21)$. The results herein indicate that after a bacterial enteritis, recovery of intestinal structure and function is delayed in the malnourished host. In infected undernourished animals, the injury sustained by the jejunum was more severe and that sustained by the ileum was both more severe and prolonged when compared to infected animals on a normal diet.

Acknowledgments. The authors thank A. Buret, G. Curtis, J. Hardin, K. Opleta, and K. van der Lee for expert technical assistance and G. Hardy for secretarial assistance.

\section{REFERENCES}

1. Chen LC 1983 Interactions of diarrhea and malnutrition. In: Chen LC Scrimshaw NS (eds) Diarrhea and Malnutrition. Plenum Press, New York pp 3-19

2. Black RE, Brown $\mathrm{KH}$, Becker S 1984 Malnutrition is a determining factor in diarrheal duration, but not incidence among young children in a longitudina study in rural Bangladesh. Am J Clin Nutr 39:87-94

3. Pai $\mathrm{CH}$, Mors V, Seemayer TA 1980 Experimental Yersinia enterocolitica enteritis in rabbits. Infect Immun 28:238-244

4. O'Loughlin EV, Humphreys G, Dunn I, Kelly J, Lian CJ, Pai C, Gall DG 1986 Clinical morphological and biochemical alterations in acute intestinal yersinosis. Pediatr Res 20:602-608

5. Dalquist A 1968 Assay of intestinal disaccharidases. Anal Biocehm 22:99-107

6. Lowry OH, Rosenbrough NJ, Farr AL, Randall RJ 1951 Protein measurement with the folin phenol reagent. J. Biol Chem 193:265-275

7. Hinegardner R 1971 An improved fluorometric assay for DNA. Anal Biocehm 39:197-201

8. Shepherd R, Hamilton JR, Gall DG 1980 The postnatal development of sodium transport in the proximal small intestine of the rabbit. Pediatr Res $14: 250-253$

9. Clarkson TW, Toole SR 1964 Measurement of short-circuit current and ion transport across the ileum. Am J Physiol 206:658-668

10. O'Loughlin EV, Lian CJ, Pai C, Gall DG 1986 Effect of acute Yersinia enterocolitica on small intestinal solute transport in vitro. Gastroenterology 90:1573(abstr)

11. Suskind R 1975 Gastrointestinal changes in the malnourished child. Pediatr Clin N Am 22:873-883

12. Hatch TF, Lebenthal E, Branski D, Krasner J 1979 The effect of early postnatal acquired malnutrition on intestinal growth, disaccharidases and enterokinase. J Nutr 109:1874-1879

13. Guiraldes E, Hamilton JR 1981 Effect of chronic mainutrition on intestinal structure, epithelial renewal and enzymes in suckling rats. Pediatr Res 15:930-934

14. Butzner JD, Gall DG 1988 Impact of protein-calorie malnutrition on the developing intestine. Biol Neonate (in press)

15. Rose PM, Hopper AF, Wannemacher RW 1971 Cell population changes in the intestinal mucosal of protein-depleted or starved rats: 1. Changes in mitotic cyst time. J Cell Biol 50:887-892

16. Jambunathan LR, Neuhoff D, Younoszai MK 1981 Intestinal disaccharidases in malnourished infant rats. Am J Clin Nutr 34:1879-1884. 
17. Rossi TM, Lee PC, Young CM, Lerner A, Lebenthal E 1986 Effect of nutritional rehabilitation on the development of intestinal brush border disaccharidases of postnatally malnourished weanling rats. Pediatr Res disaccharidases
20:793-797

18. Yamada K, Goda S, Bustamante S, Koldovsky O 1983 Different effect of starvation on activity of sucrase and lactase in rat jejunoileum. Am J Physiol 244:G449-G455

19. Butzner JD, Butler DG, Miniats OP, Hamilton JR 1985 Impact of chronic protein-calorie malnutrition on small intestinal repair after acute viral enteritis: a study in gnotobiotic piglets. Pediatr Res 19:476-481

20. Marciani P, Lindi C, Faelli A, Esposito G 1987 Effects of semistarvation on transintestinal D-glucose transport and D-glucose uptake in brush border and basolateral membranes of rat enterocytes. Pflugers Arch 408:220-223

21. Chandra RK 1986 Nutritional regulation of immunity and infection: from epidemiology to phenomenology to clinical practice. J Pediatr Gastroenterol Nutr 5:844-852 